\title{
Comment on: "Switching Reference Medicines to Biosimilars: A Systematic Literature Review of Clinical Outcomes"
}

\author{
Antonio Pires $^{1} \cdot$ Kavitha Goyal $^{1} \cdot$ Andrew Greenspan $^{1}$
}

Published online: 21 May 2018

(C) The Author(s) 2018

\section{Dear Editor,}

Switching between innovator biologics and biosimilars is an important topic that will benefit from additional scientific exploration to inform public health decisions and the safety of patients who may be asked to switch. A recent article by Cohen et al. [1] attempts to address this complex issue. We describe herein some of the limitations of the paper and over-interpretation of the available data.

The title and journal heading describe the paper as a systematic literature review; however, the steps and elements required for a Cochrane systematic review are absent [2]. A total of 90 studies were selected, 54 of which were on large molecules (mainly anti-TNF agents) including both randomized clinical trial (RCT) data and mostly recent, small real-world evidence (RWE) studies ( $<100$ patients per study) not yet published in peer-reviewed journals. Although much of the data selected is reflective of this being an evolving topic, a clear objective, outcome specification, and grading of the quality of evidence are lacking and no independent review committee was assigned to this work. At a minimum, data should have been weighted to reflect their relative strength. The evidence covered at least 12 different innovator biologics across more than 14 different disease states and we believe that the therapeutic actions of drugs, the populations, study

This letter refers to the original article available at https://doi.org/10. 1007/s40265-018-0881-y.

Andrew Greenspan agreensp@its.jnj.com

1 Janssen Pharmaceuticals, 800 Ridgeview Drive, Horsham, PA 19044, USA types, and study outcomes are too diverse to apply a single approach to the review and draw any specific conclusions [2].

The authors did describe different data sets showing positive outcomes or no negative consequences associated with switching to a biosimilar, particularly the larger RCTs; however, given the breadth of drugs reviewed, many relevant studies were overlooked with inconsistencies in the approach to data presentation and evaluation. RCTs and RWE that showed unfavorable outcomes associated with switching from innovator infliximab to an infliximab biosimilar were available before the cutoff date of 30 June 2017 and were either excluded or not described. For example, in the switch portion of the two RCTs PLANETAS [3] and Japanese rheumatoid arthritis studies [4], an increase in adverse events was observed in the arm that switched to CT-P13; however, this is not described.

In RWE, Tweehuysen et al. [5] and DANBIO [6] also noted higher than expected discontinuation rates after switch to CT-P13, and either it was not mentioned or it was not fully described. Additional studies in patients with either rheumatologic diseases or IBD in Italy, Turkey, and France also showed higher discontinuation rates or adverse clinical outcomes in patients who switched, and were not described [7-9]. Other inconsistencies relate to the authors' excluding a study from Germany [10] showing unfavorable outcomes with switching that became available shortly after the cut-off date and, in contrast, including another study showing favorable outcomes for the adalimumab biosimilar GP2017, also made available post cut-off date.

Additionally, the findings of Yazici et al. [11], which demonstrated higher treatment discontinuations and shorter time to discontinuation for CT-P13 as compared to the innovator infliximab in rheumatologic populations, were 
dismissed by the authors as chance. However, the replication of these findings in the same dataset and time period by Phillips et al. [9] was not mentioned.

The authors highlight three multiple switch studies (in contrast to the single switch studies described above) between different innovator products and their respective biosimilars: filgrastim, etanercept, and adalimumab. We caution that these data are not generalizable to other biologics. The conclusion that there are no differences in efficacy or safety based on a limited number of switch studies in these unrelated molecules should be questioned. Although we do agree that pharmacovigilance is critical to ensure patient safety, it cannot serve as a substitute for the evidence required to demonstrate interchangeability between innovators and biosimilars as defined by the US Food and Drug Administration (FDA) [12]. Importantly, the multiple switch studies described in this paper do not meet the trial design requirements specified by the FDA to demonstrate interchangeability, and until such studies are conducted, patient-reported loss of effect and/or patient discontinuation may be the only indicators of drug failure that real-world evidence can provide.

The authors refer to manufacturing changes in a specific innovator biologic over time as "de facto switching," and note that publications on this topic were not retrieved in the search for this paper. The literature does not address these changes as switches because, by definition, they are not switches since all biologic manufacturers need to comply with the ICH Q5E guidance [13] on comparability data when submitting changes in manufacturing process for regulatory approval.

In our opinion, the literature review conducted by Cohen et al. [1] did not comprehensively address the question as to whether switching from innovator to biosimilar could lead to altered clinical outcomes. We believe that the lack of comprehensive and systematic inclusion of relevant studies, appropriate weighting to reflect strength of evidence, and the combining of results across drugs, diseases, and type of studies, challenge the conclusion reached. Although RCT data have demonstrated biosimilarity between biosimilars and their innovators, the outcomes of switching from innovator to a biosimilar-including effectiveness, safety, immunogenicity, and persistency in the real world as well as multiple switches in the context of interchangeability, remain to be fully elucidated. Additional studies are needed on this important question.

\section{Compliance with ethical standards}

Conflict of interest All authors are employees of Janssen Pharmaceuticals and own or owned stock in Johnson \& Johnson.

Open Access This article is distributed under the terms of the Creative Commons Attribution-NonCommercial 4.0 International License (http://creativecommons.org/licenses/by-nc/4.0/), which permits any noncommercial use, distribution, and reproduction in any medium, provided you give appropriate credit to the original author(s) and the source, provide a link to the Creative Commons license, and indicate if changes were made.

\section{References}

1. Cohen HP, Blauvelt A, Rifkin RM, Danese S, Gokhale SB, Woollett G. Switching reference medicines to biosimilars: a systematic literature review of clinical outcomes. Drugs. 2018;78(4):463-78.

2. Higgins JPT, Green S (eds). Cochrane Handbook for Systematic Reviews of Interventions Version 5.1.0 [updated March 2011]. The Cochrane Collaboration, 2011. http://handbook.cochrane. org. Accessed 28 Mar 2018

3. Park W, Miranda P, Brzosko M, et al. Efficacy and safety of CTP13 (infliximab biosimilar) over two years in patients with ankylosing spondylitis: comparison between continuing with CTP13 and switching from infliximab to CT-P13. Poster presented at: 2013 ACR/ARHP Annual Meeting; San Diego, CA; October 25-30. Abstract L15

4. Tanaka Y, Yamanaka H, Takeuchi T, Inoue M, Saito K, Saeki Y, et al. Safety and efficacy of CT-P13 in Japanese patients with rheumatoid arthritis in an extension phase or after switching from infliximab. Mod Rheumatol. 2017;27(2):237-45.

5. Tweehuysen L, van den Bemt BJF, van Ingen IL, et al. Clinical and immunogenicity outcomes after switching treatment from innovator infliximab to biosimilar infliximab in rheumatic diseases in daily clinical practice [abstract]. Arthritis Rheumatol. 2016; 68 (suppl 10)

6. Glintborg B, Sorensen IJ, Loft AG, et al. A nationwide non-medical switch from originator infliximab to biosimilar CT-P13 in 802 patients with inflammatory arthritis: 1-year clinical outcomes from the DANBIO registry. Ann Rheum Dis. 2017;76(8):1426-31.

7. Avouac J, Molto A, Abitbol V, et al. Systematic Switch from innovator infliximab to biosimilar infliximab in inflammatory rheumatic diseases in daily clinical practice: the experience of Cochin Hospital, Paris, France. Ann Rheum Dis. 2017;76(suppl 2):831.

8. Fiorino G, Manetti N, Armuzzi A, et al. The PROSIT-BIO cohort: A prospective observational study of patients with inflammatory bowel disease treated with infliximab biosimilar. Inflamm Bowel Dis. 2017;23(2):233-43.

9. Phillips K, Juday T, Zhang Q, Keshishian A. Economic outcomes, treatment patterns, and adverse events and reactions for patients prescribed infliximab or CT-P13 in the Turkish population. Ann Rheum Dis. 2017;76(suppl 2):835.

10. Ewara E, Marrache A, Goyal K, Ellis L, Baraliakos X. Realworld retention patterns of patients treated with innovator or biosimilar infliximab or switched from innovator to biosimilar infliximab in Germany [AMCP abstract U11]. J Manag Care Spec PH. 2017;23(10-a):S84.

11. Yazici Y, Xie L, Ogbomo A, et al. A descriptive analysis of realworld treatment patterns in a Turkish rheumatology population that continued innovator infliximab (Remicade) therapy or switched to biosimilar infliximab [abstract]. Arthritis Rheumatol. 2016; 68 (suppl 10)

12. US Dept HHS, Food and Drug Administration. Guidance for industry: draft guidance: considerations in demonstrating interchangeability with a reference product. 2017. https://www.fda. gov/downloads/Drugs/GuidanceComplianceRegulatoryInforma tion/Guidances/UCM537135.pdf. Accessed 28 Mar 2018

13. International conference on harmonisation: guidance on Q5E comparability of biotechnological/biological products subject to changes in their manufacturing process. https://www.ich.org/ fileadmin/Public_Web_Site/ICH_Products/Guidelines/Quality/ Q5E/Step4/Q5E_Guideline.pdf. Accessed 28 Mar 2018 